\title{
VANADIUM-MODIFIED MOLECULAR SIEVES: PREPARATION, CHARACTERIZATION AND CATALYSIS
}

Ângela A. Teixeira-Neto ${ }^{\#}$

Departamento de Química Fundamental, Instituto de Química, Universidade de São Paulo, CP 26077, 05508-000 São Paulo - SP, Brasil

Leonardo Marchese

Dipartimento di Scienze e Tecnologie Avanzate, Università del Piemonte Orientale "A. Avogadro", Via Bellini 25G, I-15100

Alessandria, Italia

Heloise O. Pastore*

Departamento de Química Inorgânica, Instituto de Química, Universidade Estadual de Campinas, CP 6154,

13084-862 Campinas-SP, Brasil

Recebido em 13/5/08; aceito em 29/8/08; publicado na web em 5/2/09

\begin{abstract}
Vanadium-containing molecular sieves are redox catalysts and are good candidates as substitutes for oxide-supported $\mathrm{V}_{2} \mathrm{O}_{5}$ in a number of reactions. These materials have the advantage of presenting better dispersion of vanadium species, as well as shapeselective properties and controllable acidities. They may be prepared by one-pot synthesis or by post-synthesis methods and a number of techniques such as diffuse reflectance UV-visible spectroscopy, ${ }^{51} \mathrm{~V}$ nuclear magnetic resonance and electron paramagnetic resonance, to name but a few, have been used to characterize these materials. In this review, methods of preparation of vanadiummodified molecular sieves, their characterization and applications in catalysis are discussed.
\end{abstract}

Keywords: vanadium; oxidation catalysts; zeolites.

\section{INTRODUCTION}

The incorporation of transition metals in zeolite lattices is a research area of great interest in the catalysis field. The isomorphous substitution of metals like iron, chromium or zinc in the framework of molecular sieves has been proved and discussed. ${ }^{1}$ Vanadium, in special, is known for its potential as a redox catalyst, particularly when homogeneously dispersed in solid supports. ${ }^{2}$

Molecular sieves containing vanadium species provide not only the desired redox properties, but the likewise structural and shapeselective properties which are characteristic of this sort of material. In the specific case of microporous crystalline materials, they have the advantage of presenting high hydrothermal stabilities, high surface areas and pore volumes and controlled acidity. On the other hand, mesoporous materials may provide good catalysts for the oxidation of aromatic molecules, which are too large to have access to catalytic sites in microporous materials.

The aim of this paper is to present a state-of-the-art review of these promising redox shape-selective catalysts, focusing on the relationship of the preparation methods with the kind of vanadium species present and their role in catalysis.

\section{PREPARATION METHODS AND STRUCTURE OF VANADIUM SITES}

\section{One-pot synthesis}

In Table 1 are listed the first occurrences of the known structures of vanadium containing molecular sieves in the literature, prepared by the introduction of the vanadium source in the synthesis gel.

*e-mail: gpmmm@iqm.unicamp.br

\#Endereço atual: Universidade Federal do ABC, Rua Santa Adélia, 166, 09210-170 Santo André-SP

The first microporous materials containing framework vanadium atoms to be synthesized were the vanadoaluminophosphates (VAPO). A patent deposited by Union Carbide in $1985^{3}$ claims the production of VAPO with AFI structure, VAPO-5, but this material still presented some impurities. Synthesis of pure VAPO-5 was achieved only in 1990 by Montes et al. ${ }^{4}$ The structures VAPO- $11,{ }^{5}-21,{ }^{5}-31,{ }^{6}-17,{ }^{7}$ $-41^{8}$ and $-18^{9}$ were successfully prepared over the last three decades (Table 1). Recently, a mesoporous VAPO with hexagonal MCM-41like pores was also synthesized. ${ }^{10}$

In general, as-synthesized VAPOs present $\mathrm{V}^{4+}$ ions occupying the positions of phosphorus atoms (Scheme 1, structure A). The calcination process leads to the total oxidation of $\mathrm{V}^{4+}$ to $\mathrm{V}^{5+}$. This process is reversible by reduction under $\mathrm{H}_{2}$ atmosphere. The structure of the vanadium ion in the calcined sample is not a consensus in all reports. Some authors claim that $\mathrm{V}^{5+}$ still bears a $\mathrm{V}=\mathrm{O}$ bond ${ }^{11}$ (Scheme 1, structure $\mathrm{C}$ ) while others claims that the in the majority of vanadium sites $\mathrm{V}^{5+}$ is bonded to four $-\mathrm{O}-\mathrm{Al} \equiv$ (Scheme 1, structure B) ${ }^{7,12}$ Typically, vanadium amounts in VAPO materials lie between 0.5 to $1 \%$. $^{7,12}$

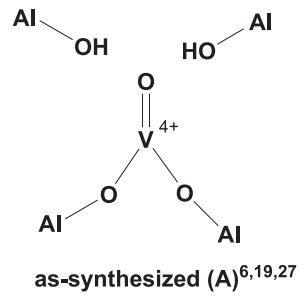

Scheme1

Since the late $80^{\prime}$ s, vanadium ions began to be introduced in aluminosilicate structures (Table 1). The most studied microporous vanadosilicate prepared by one-pot synthesis is the vanadosilicalite VS-1, which has MFI structure and will be called [V]-MFI from now on. ${ }^{13} \mathrm{~A}$ very complete physico-chemical characterization of this 
Table 1. Vanadium-containing molecular sieves prepared by one-pot syntheses

\begin{tabular}{|c|c|c|c|}
\hline Material & V source & Year & Ref. \\
\hline VAPO-5 (impure) & $\mathrm{V}_{2} \mathrm{O}_{5}$ & 1985 & 3 \\
\hline VAPO-11 & $\mathrm{V}_{2} \mathrm{O}_{5}$ & 1985 & 5 \\
\hline VAPO-21 & $\mathrm{V}_{2} \mathrm{O}_{5}$ & 1985 & 5 \\
\hline [V]-MEL & $\mathrm{VOSO}_{4}$ & 1989 & 76 \\
\hline VAPO-5 (pure) & $\mathrm{V}_{2} \mathrm{O}_{5}$ & 1990 & 12 \\
\hline [V]-MFI & $\mathrm{VCl}_{3}$ & 1991 & 13 \\
\hline [V]-NCL-1 & $\mathrm{VOSO}_{4}$ & 1992 & 77 \\
\hline [V]-MCM-41 & $\mathrm{VOSO}_{4}$ & 1994 & 20 \\
\hline [V]-ZSM-48 & $\mathrm{VOSO}_{4}$ & 1994 & 78 \\
\hline [V]-MTW & $\mathrm{VOSO}_{4}$ & 1995 & 79 \\
\hline [V]-HMS & $\mathrm{VOSO}_{4}$ & 1995 & 22 \\
\hline VAPO-31 & $\mathrm{V}_{2} \mathrm{O}_{5}$ & 1996 & 6 \\
\hline [V]-MFI & $\mathrm{VOSO}_{4}$ & 1996 & 59 \\
\hline [V]-MCM-48 & $\mathrm{VOSO}_{4}$ & 1996 & 67 \\
\hline [V]-beta & $\mathrm{V}_{2} \mathrm{O}_{5}$ & 1997 & 80 \\
\hline AM-6 & $\mathrm{VOSO}_{4}$ & 1997 & 81 \\
\hline [V]-FER & $\mathrm{VOSO}_{4}$ & 1999 & 61 \\
\hline VAPO-17 & $\mathrm{VOSO}_{4}$ & 2000 & 7 \\
\hline [V,Al]-MCM-41 & $\mathrm{VOSO}_{4}$ & 2002 & 23 \\
\hline AM-13, AM-14 & $\mathrm{VOSO}_{4}$ & 2002 & 82 \\
\hline VAPO-41 & $\mathrm{V}_{2} \mathrm{O}_{5}$ & 2003 & 8 \\
\hline VAPO-18 & $\mathrm{V}_{2} \mathrm{O}_{5}$ & 2004 & 9 \\
\hline [V,Al]-MWW & $\mathrm{VOSO}_{4}$ & 2005 & 27 \\
\hline mesoporous VAPO & $\mathrm{VOSO}_{4}$ & 2005 & 10 \\
\hline
\end{tabular}

material has been carried out by Centi et al. ${ }^{14}$ The authors used a combination of techniques, including wide-line ${ }^{51} \mathrm{~V}$ nuclear magnetic resonance (NMR), X ray photoelectron spectroscopy (XPS), electron paramagnetic resonance (EPR) and diffuse reflectance UV-visible spectroscopy (DR-UV-Vis) to propose a model of the coordination environment of tetrahedral $\mathrm{V}^{5+}$ sites in the silicalite structure (Scheme 2). Besides tetrahedral $\mathrm{V}^{5+}$ extractrable $\mathrm{V}_{2} \mathrm{O}_{5}$ domains were found in the calcined sample.

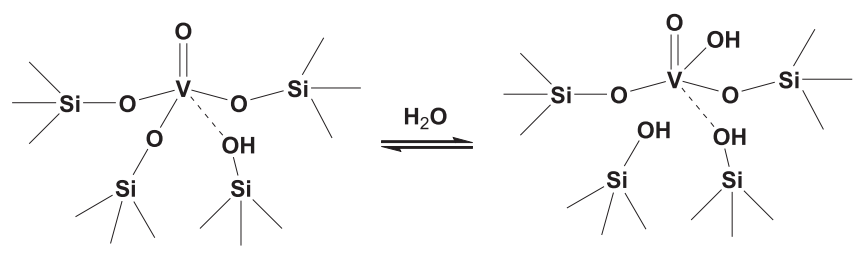

Scheme 2

Sen et al. ${ }^{15}$ proposed similar structures for calcined [V]-MEL (VS-2) by combining ${ }^{51} \mathrm{~V}$ liquid state NMR and EPR data. Moreover, the authors proposed structures for vanadium environment in the gels, as-synthesized, calcined (hydrated and dehydrated), and reduced samples. The proposed mechanism for oxidation/reduction of vanadium sites in the calcined samples is illustrated in Scheme 3.

The symmetry of vanadium redox sites is also a matter of discussion. By means of cyclic voltammetry and EPR studies, Venkatathri
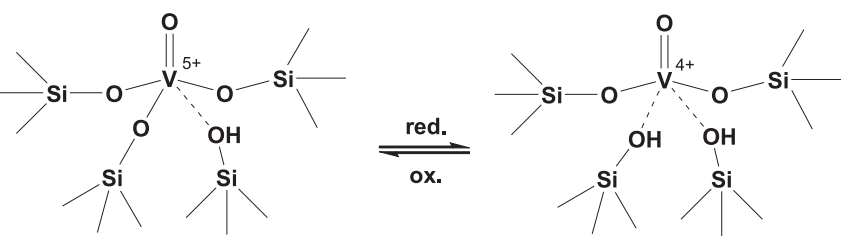

Scheme 3

et al. ${ }^{16}$ found that in [V]-MFI and [V]-MEL vanadium redox sites are found in distorted tetrahedral symmetry and square pyramidal symmetry, according to their location in the zeolite framework. Also, they assumed that the square pyramidal species are formed from the oxidation of $\mathrm{V}^{4+}$ ions present in the as-synthesized samples, while the distorted tetrahedral species are formed directly during the synthesis procedure. A combination of ESR, photoluminescence spectroscopy and XAFS studies, on the other hand, carried out by Anpo et al. ${ }^{17}$ in 2003, revealed the presence of trigonal pyramid symmetry only, with different bond angles in [V]-MFI and [V]-MEL. In this last study, only dehydrated samples were analyzed, which indicates the possibility that the square pyramidal sites found by Venkatathri et al. were generated by the coordination of water molecules.

It is interesting to note that most authors report that dehydrated vanadium-containing molecular sieves are white in color, while hydrated samples present a yellow color whose intensity depends on the vanadium content. This mechanism is often related to a change in coordination of $\mathrm{V}^{5+}$ from tetrahedral to octahedral, by interaction with one or two water molecules. ${ }^{18}$ In fact, ESR results indicate that, in [V]-MFI, most of the vanadium species exist on the surface of the material, where $\mathrm{H}_{2} \mathrm{O}$ molecules are easily accessible and thus distorted octahedral $\mathrm{VO}^{2+}$ species can be easily generated. ${ }^{17}$

Mesoporous vanadium-containing molecular sieves are another important class of materials that have been developed during the last decades. MCM-41 was first synthesized in 1992 by Mobil researchers ${ }^{19}$ and the first time that [V]-MCM-41 appeared was in 1994 (Table 1). ${ }^{20}$ It presents a hexagonal pore structure very similar to that of MCM-41 with a $\mathrm{Si} / \mathrm{V}$ ratio equal to 60 and is prepared in the absence of $\mathrm{V}_{2} \mathrm{O}_{5}$ domains. Cubic [V]-MCM-48 has also been prepared, ${ }^{21}$ as well as the also hexagonal [V]-HMS, which is prepared using primary amines as templates..$^{22}$

A vanadoaluminosilicate with MCM-41 structure, [V,Al]MCM-41, has been synthesized in 2002. ${ }^{23}$ As far as we know, only few molecular sieves prepared by one-pot synthesis contained both $\mathrm{V}$ and $\mathrm{Al}$ simultaneously, such as [V,Al]-MCM- $41^{23}$ and the microporous [V,Al]-beta ${ }^{24}$ and $[\mathrm{V}, \mathrm{Al}]-\mathbf{M W W} .^{25}$ These materials present very interesting properties as bifunctional acid/redox catalysts.

\section{Other methods}

Besides one-pot syntheses, vanadium ions may be introduced in molecular sieves by post-synthesis methods. Some vanadium containing molecular sieves prepared by such methods, which include impregnation, chemical vapor deposition, between others are listed in Table 2.

A simple approach to a post-synthesis vanadium incorporation is to proceed with ion-exchange of protons or sodium ions for vanadyl cations, $\mathrm{VO}^{2+}{ }^{26,}{ }^{27}$ For this procedure, vanadyl sulfate is commonly used (Table 2). The difficulty in this method is that this salt hydrolyses in $\mathrm{pH}$ values higher than 2.8 , originating $\mathrm{V}_{2} \mathrm{O}_{5}$ domains. On the other hand, low $\mathrm{pH}$ values lead to a competition between $\mathrm{H}^{+}$and $\mathrm{VO}^{2+}$ ions, which may cause the incorporation of very limited vanadium amounts. To achieve higher amounts of metal incorporation, impregnation is another possibility of post-synthesis vanadium introduction, ${ }^{28-30}$ but 
Table 2. Vanadium containing molecular sieves prepared by other methods

\begin{tabular}{|c|c|c|c|c|}
\hline Material & Incorporation method & V source & Year & Ref. \\
\hline V-MCM-48 & wet impregnation & $\mathrm{V}(\mathrm{O}-$ propi $)$ & 1996 & 83 \\
\hline V-BOR & wet impregnation & NH4VO3 & 1996 & 28 \\
\hline $\mathrm{V}-\mathrm{Y}$ & wet impregnation & VOSO4 & 1997 & 29 \\
\hline V-MCM-48 & gas deposition & $\mathrm{VO}(\mathrm{acac}) 2$ & 1998 & 84 \\
\hline $\begin{array}{l}\text { VO-MFI, } \\
\text { VO-MOR, } \\
\text { VO-Y, VO-X }\end{array}$ & ion-exchange & VOSO4 & 1998 & 26 \\
\hline V-MFI & $\begin{array}{c}\text { chemical vapor } \\
\text { deposition }\end{array}$ & $\mathrm{VOCl} 3$ & 1998 & 26 \\
\hline V-beta & $\begin{array}{l}\text { wet impregnation in } \\
\text { dealuminated zeolite }\end{array}$ & NH4VO3 & 1998 & 33 \\
\hline V-ALPO-5 & wet impregnation & VOSO4 & 2000 & 30 \\
\hline V-beta, V-MFI & solid state ion-exchange & $\mathrm{V} 2 \mathrm{O} 5$ & 2004 & 31 \\
\hline V-MCM-48 & ion-exchange & Na3VO4 & 2005 & 85 \\
\hline VO-MWW & ion-exchange & VOSO4 & 2005 & 27 \\
\hline
\end{tabular}

this method leads to $\mathrm{V}_{2} \mathrm{O}_{5}$ aggregates, which are often not interesting for catalysis. Still another approach is based on methods that do not involve contact with an aqueous solution: chemical vapor deposition (CVD), solid state ion-exchange and sublimation. ${ }^{26,31,32}$ In these methods the metallic species is vaporized at high temperatures and/or at low pressures and deposited on the material surface. The advantage is that they avoid the restricted diffusion of solvated oligomer species in aqueous exchange, which leads to poorly dispersed oxide domains at external surfaces.

A study comparing the different vanadium-modified microporous molecular sieves preparation methods was carried on by Wachs et al. ${ }^{26}$ and revealed the presence of isolated structural vanadium species in materials prepared by one-pot synthesis and of $\mathrm{VO}^{2+}$ species in the materials prepared by ion-exchange (non temperature treated, $\mathrm{pH}$ values lower than 2.8). In materials prepared by CVD it was observed the presence of $\mathrm{V}_{2} \mathrm{O}_{5}$ aggregates in the interior of the cavities and/ or on the surface of the molecular sieves, as well as $\mathrm{VO}^{2+}$ cations in some cases. The characterization techniques used for this study were DR-UV-Vis, EPR and XPS. According to the authors, it is possible to distinguish between extra- and intra-zeolite vanadium oxide aggregates by the use of XPS.

Dimitrova et al. ${ }^{31}$ have prepared vanadium-modified molecular sieves starting from borosilicates beta and MFI, from which the boron species were extracted and then a solid-state ion-exchange with $\mathrm{V}_{2} \mathrm{O}_{5}$ was performed. Although the authors claim that only two different $\mathrm{VO}^{2+}$ species were found, as counter-ions and in silanol nests, it is clear from the bands at approximately $400 \mathrm{~nm}$ in DR-UV-Vis spectra that $\mathrm{V}_{2} \mathrm{O}_{5}$ aggregates are present. ${ }^{31}$

The group of Prof. Che $\mathrm{Ch}^{33-42}$ performed an exhaustive work on the synthesis and characterization of vanadium-modified beta zeolite. They first prepared it on 1998, by the dealumination of zeolite beta with an acid solution and then allowing it to contact with a $\mathrm{NH}_{4} \mathrm{VO}_{3}$ aqueous solution. ${ }^{33}$ The authors have proposed, mainly by using photoluminescence spectroscopy, three principal vanadium species in V-beta $(\alpha, \beta$ and $\gamma)$, depending on the location of the atom in the zeolite lattice (Scheme 4). ${ }^{35}$ This method seems thus to introduce vanadium ions as framework species, but this procedure is possible in this case only because beta-zeolite is easily dealuminated when in contact with acid solutions, which is not possible for all zeolites.

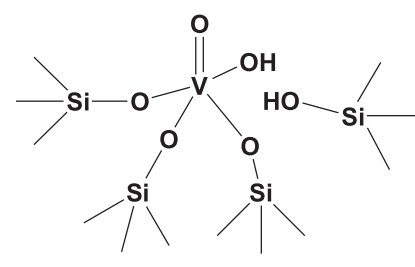

Structure A ( $\alpha$ species)

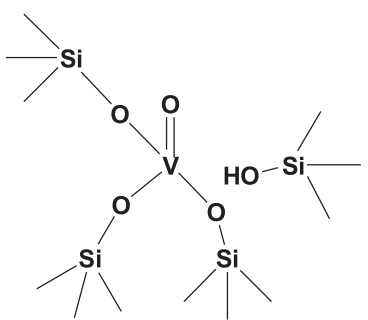

Structure B

( $\beta$ species)

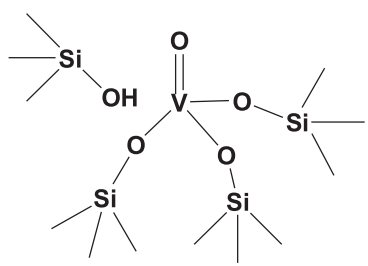

Structure C

( $\gamma$ species $)$

Scheme 4

\section{USE IN CATALYSIS}

In this section data obtained using vanadium-modified molecular sieves for catalysis until this moment will be presented. Some of the most representative data for microporous vanado(alumino)silicates, microporous vanadoaluminophosphates and mesoporous materials, as well as some studies that compare catalytic activities of microporous and mesoporous materials, will be explored.

Vanadium-modified molecular sieves are usually employed as catalysts in oxidation reactions, although many exceptions can be found. By far the most tested reaction is propane oxidative dehydrogenation $(\mathrm{ODH})$ for propene production and, in some cases, the results seem very promising when compared to the traditional supported $\mathrm{V}_{2} \mathrm{O}_{5}$ catalysts.", 25, 28, 43-50 The propane $\mathrm{ODH}$ reaction is an interesting alternative to the direct dehydrogenation, as it is an exothermic reaction:

$\mathrm{C}_{3} \mathrm{H}_{8}+1 / 2 \mathrm{O}_{2} \rightarrow \mathrm{C}_{3} \mathrm{H}_{6}+\mathrm{H}_{2} \mathrm{O} \quad \Delta \mathrm{H}^{\mathrm{o}}=-118 \mathrm{~kJ} \mathrm{~mol}^{-1}$

Usually, some side products are obtained, such as carbon oxides and organic molecules such as ethene, acrolein, acrylic and acetic acid. The choice of the catalyst is thus very important in order to minimize the yield of these side products.

In general, mesoporous materials are used in reactions that comprehend bulky molecules, such as aromatics, while microporous materials are used for reacting small molecules.

\section{Microporous materials}

\section{Vanadosilicates and vanadoaluminosilicates}

As it was the first vanadium-containing molecular sieve to be synthesized and the better characterized, [V]-MFI is the most used as a catalyst. In some reactions, for instance, selective production of hydrazine by oxidation of ketone- $\mathrm{NH}_{3}$ system by $\mathrm{H}_{2} \mathrm{O}_{2}$ it is clearly more active than its titanium analogue, [Ti]-MFI, ${ }^{51}$ but in some cases, as for reduction of $\mathrm{NO}_{\mathrm{x}}{ }^{52}$ it is less active. In this last case, however, the simultaneous incorporation of vanadium and titanium increase the activity of the catalyst, revealing a cooperative effect between the two metals. In the oxidation of ethylbenzene ${ }^{53}$ it proved to be less active than [Sn]-MFI. In oxidation of para-chlorotoluene to para- 
chlorobenzaldehyde ${ }^{54}$ it was more active than [V]-MEL and much more active and selective than vanadium-impregnated MFI and MEL zeolites. The oxidation of aromatic molecules is an important process, as oxygenated aromatic compounds are widely used industrially.

In propane ODH, high selectivities with [V]-MFI were obtained, but only at very low conversions, such as $5 \% .{ }^{28}$ Using a membrane constituted by [V]-MFI, Julbe et al $^{46}$ were able to achieve a maximum yield of $7 \%$ of propene and an activity much higher that that of MFI zeolite. When [V,Al]-MWW was used for propane ODH, propene yields of $5 \%$ were achieved, with reaction temperatures $\left(350-550{ }^{\circ} \mathrm{C}\right)$ much lower than those used with the [V]-MFI membrane (550-650 $\left.{ }^{\circ} \mathrm{C}\right){ }^{55}$ It is important to note that acidity of [V,Al]-MWW may be tuned by exchange with alkaline ions, which provide mild acid sites that collaborate with vanadium sites to promote higher selectivities towards propene.

Some studies relate the vanadium species found in [V]-MFI with catalytic activity. In the transformation of ethanol, for instance, Kannan et al. ${ }^{56}$ claim that only $\mathrm{V}=\mathrm{O}$ species are selective for acetaldehyde while both $\mathrm{V}=\mathrm{O}$ and $\mathrm{V}-\mathrm{O}-\mathrm{Si}$ species are selective for diethyl ether. This reaction is important for the production of value-added chemicals from bio-based ethanol. The study was done with the aid of NMR and ESR techniques. Also, the authors noted that intrinsic activity is 10 times larger for framework vanadium than for extra-framework species. Tetrahedrally coordinated $\mathrm{V}=\mathrm{O}$ species are also responsible for the activity in the photocatalytic decomposition of $\mathrm{NO}$, because they are excited to a $\left(\mathrm{V}^{4+}-\mathrm{O}\right) *$ state. ${ }^{57}$ Its activity is much higher than that of $\mathrm{SiO}_{2}$-supported $\mathrm{V}_{2} \mathrm{O}_{5}$.

In disagreement with the results presented in the previous cited studies, Wang et al. ${ }^{58}$ stated that in the methanol oxidation reaction, for the production of formaldehyde, [V]-MFI has an activity comparable to that of $\mathrm{SiO}_{2}$-supported $\mathrm{V}_{2} \mathrm{O}_{5}$, with similar selectivity. Also, they claim that the structure of vanadium species is similar in both catalysts and that [V]-MFI does not present any $\mathrm{V}=\mathrm{O}$ bonds. The $\mathrm{V}-\mathrm{O}-\mathrm{Si}$ species are thus, according to the authors, the responsible for catalytic activity. The results presented in this work are based mostly on Raman spectra, and the conclusions differ much from all the other papers on characterization of vanadium sites in [V]-MFI.

The synthesis method is a very important factor in order to obtain lattice vanadium species. When prepared in acid media, [V]-MFI presents an activity for toluene oxidation much lower than that of the sample prepared in alkaline media. ${ }^{59}$ The material prepared in acid media has a much higher amount of extractable extra-framework vanadium species, which are not active for the oxidation reaction. Toluene oxidation is an important reaction for the industrial production of benzaldehyde and benzoic acid.

When prepared by CVD, vanadium-containing MFI presents higher activity in ethane ODH than vanadium-impregnated MFI, with maximum dehydrogenation rate in the order of $1.10^{-3} \mathrm{~mol} \mathrm{~s}^{-1}$ $\mathrm{V}^{-1} .{ }^{32}$ High vanadium amounts inhibit the reaction, as $\mathrm{VO}_{\mathrm{x}}$ domains are created. Also in this work the authors claim that the active species are the $\mathrm{V}=\mathrm{O}$.

[V]-FER was used for styrene epoxidation ${ }^{60}$ and toluene oxidation. ${ }^{61}$ In the first reaction, it showed activities and selectivities to styrene oxide and benzaldehyde, respectively, similar to the ones obtained over [Ti]-FER. For both reactions impregnated materials presented low selectivity to desired products. When vanadium species are more disperse, conversion values tend to increase.

\section{Vanadoaluminophosphates (VAPOs)}

The most studied VAPO catalyst is VAPO-5, with AFI structure. For alkene epoxidation and oxidation of aromatics, VAPO-5 presented better selectivities to the desired products as homogeneous vanadium-containing systems and polymer-supported complexes, with comparable conversion values. ${ }^{62}$ Also, this catalyst did not present metal lixiviation in aqueous media. When compared to vanadium-impregnated ALPO-5 for propane ODH, VAPO-5 showed higher activities, as it presents isolated vanadium species, while ALPO-5 did not present any activity.$^{63}$ Okamoto et al. ${ }^{30}$ observed that VAPO-5 catalysts prepared with more than $1 \%$ vanadium presented extraframework species that are less selective, less active and block the access to framework active sites. A method used by the authors to increase vanadium loading without creating extraframework species was to further ion-exchange VAPO-5 with vanadyl ions, raising vanadium amount from 0.38 to $0.90 \%$. This approach increased catalytic activity of VAPO-5 in propane ODH.

For some reactions, for instance, cyclohexane oxidation, AEL strucutre (VAPO-11) provided better results than AFI (VAPO-5), which illustrates the importance of the structure in catalysis. ${ }^{64} \mathrm{Cy}$ clohexane oxidation leads to cyclohexanol and cyclohexanone and is usually catalyzed by cobalt compounds:

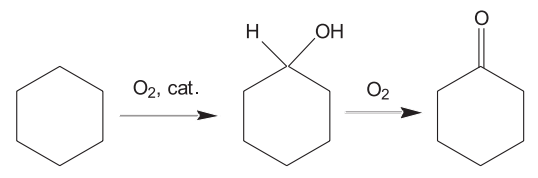

In this reaction cobalt and chromium containing catalysts provided better results than VAPOs, which led to deep oxidation products. The structure AEI (VAPO-18) was compared to AFI for ethane ODH, for ethene production, and it proved to be more selective. ${ }^{9}$ The simultaneous incorporation of cobalt facilitates vanadium incorporation and improves selectivity.

For both transformation of camphene ${ }^{65}$ and transformation of cyclohexanol, ${ }^{66}$ the presence of vanadium ions did not improve catalytic activity. For those specific reactions, in fact, acid sites present in SAPO catalysts were more interesting than vanadium itself.

\section{Mesoporous materials}

[V]-MCM-41 and [V]-HMS have been widely used in catalysis. [V]-MCM-48, however, is cited in a much smaller number or papers. When applied in catalysis, those materials are often compared to their titanium-containing analogues. When used in benzene hydroxylation to phenol, for instance, [V]-MCM-41 was less active than [Ti]-MCM-41, but from the metal-HMS catalysts, [V]-HMS was the most active. ${ }^{67}$ In this reaction, selectivity to phenol achieved $100 \%$ at low conversion values $(\sim 10 \%)$.

The vanadium source is an important factor when it comes to the synthesis of [V]-MCM-41. Selvam et al. ${ }^{68}$ reported that vanadium incorporation varies according to its source: tetravalent salts seem to be more efficient. For catalysis purposes, then, materials containing higher amounts of well dispersed vanadium ions, prepared from tetravalent sources, are more active. Those materials, with vanadium amounts variyng from 0.2 to $1.2 \%$, were tested on cyclohexane oxidation. When tested in the same reaction, [V]-MCM-48 presented high conversions and a minimal vanadium leaching. ${ }^{69}$

When compared to $\mathrm{SiO}_{2}$-supported $\mathrm{V}_{2} \mathrm{O}_{5}$ in propane selective oxidation, [V]-MCM-41 and [V]-MCM-48 containing up to $1 \%$ vanadium were much more selective. ${ }^{70}$ Materials containing polymeric domains lead to formation of oxygenated products such as acrolein, acetaldehyde and acetic acid.

A method developed by ion-exchange of the cetyltrimethylammonium template from MCM-41 with $\mathrm{VO}\left(\mathrm{C}_{2} \mathrm{O}_{4}\right)$ and posterior calcination led to a material that showed higher efficiency in methane partial oxidation than [V]-MCM-41 prepared by one-pot synthesis. ${ }^{71}$ 
According to the authors, VO-exchanged MCM-41 presents weakly bonded $\mathrm{V}=\mathrm{O}$ species that are more active than strongly bonded ones, generated by one-pot synthesis. For microporous materials, however, $\mathrm{V}=\mathrm{O}$ species seem to have quite similar characteristics when the material is prepared whether by one-pot synthesis or by ion-exchange. ${ }^{27}$

When prepared by one-pot synthesis [V]-HMS presented higher selectivity to benzaldehyde on toluene oxidation when compared to V-HMS prepared by molecular designed dispersion. ${ }^{72}$ The latter increases selectivity to carbon oxides.

Vanadium-containing mesoporous materials are also useful in photocatalysis. On propane photooxidation, for instance, [V]MCM-41 presented high conversion values. The selectivity of this catalyst could be further improved when titanium ions were coincorporated.

\section{Microporous versus mesoporous materials}

Few papers compare differences in catalytic activities of microporous and mesoporous vanadium-containing molecular sieves. In benzene hydroxylation, for instance, all [V]-MCM-41, [V]-MCM-48, [V]-MFI and [V]-beta were tested..$^{73}$ As benzene is a relatively bulky molecule, mesoporous materials presented higher activities, while [V]-MCM-41 was better than [V]-MCM-48.

In the oxidation of alkylsulfides [V]-MFI, [V]-MEL and [V]HMS, were tested, together with their Ti-containing analogues. ${ }^{74}$ In this case, vanadosilicates presented higher conversions than titanosilicates. Activity remained in the order [V]-HMS > [V]-MEL > [V]-MFI. Also in this case, pore diameter plays an important role in catalytic activity.

V-USY and V-Y prepared by impregnation were tested n-butane dehydrogenation. ${ }^{75}$ An $\mathrm{O}_{2}$-free atmosphere was used. V-USY showed both higher activity and selectivity, due to its higher vanadium loading and milder acidity. Both catalysts were more active than $\mathrm{Al}_{2} \mathrm{O}_{3}$-supported $\mathrm{V}_{2} \mathrm{O}_{5}$.

\section{CONCLUSIONS}

Vanadium-containing molecular sieves are important oxidation catalysts that are beginning to gain notoriety in the last years. It was shown in this review that a large number of this kind of catalysts have been, and continue to be, prepared, characterized and applied in catalytic reactions. It was observed that, in general, the most selective catalysts are the ones that present better dispersed and homogeneous vanadium species. Oxide clusters lead to deep oxidation products and often block access to the molecular sieves pores and/ or cavities. Catalysts prepared by one-pot synthesis are still the ones that best fulfill the compromise between vanadium concentration and metal dispersion. Most of the reviewed papers present materials with vanadium concentrations that go up to $1 \%$. The choice of the structure should depend on the reaction, as large molecules require mesoporous catalysts, while small molecules may benefit from the shape selectivity of microporous materials. For some applications, the incorporation of a second metal, as titanium, for instance, may lead to a cooperative effect between the two metals and good results can be obtained.

\section{REFERENCES}

1. Pastore, H. O.; Quim. Nova 1996, 19, 372.

2. Weckhuysen, B. M.; Keller, D. E.; Catal. Today 2003, 78, 25.

3. Flanigen, E. M.; Lok, B. M. T.; Patton, R. L.; Wilson, S. T.; US pat. 158976, 1985.
4. Montes, C.; Davis, M. E.; Murray, B.; Narayana, M.; J. Phys. Chem. 1990, 94, 6431.

5. Pyke, D. R.; Whitney, P.; Houghton, H.; Appl. Catal. 1985, 18, 173.

6. Venkatathri, N.; Hegde, S. G.; Sivasanker, S.; J. Chem. Soc., Chem. Commun. 1995, 151.

7. Zahedi-Niaki, M. H.; Zaidi, S. M. J.; Kaliaguine, S.; Appl. Catal., A 2000, 196, 9.

8. Venkatathri, N.; Appl. Catal., A 2003, 242, 393.

9. Concepcion, P.; Blasco, T.; Nieto, J. M. L.; Vidal-Moya, A.; MartinezArias, A.; Microporous Mesoporous Mater. 2004, 67, 215.

10. Venkatathri, N.; Srivastava, R.; Catal. Commun. 2005, 6, 177.

11. Prakash, A. M.; Kevan, L.; J. Phys. Chem. B 1999, 103, 2214.

12. Montes, C.; Davis, M. E.; Murray, B.; Narayana, M.; J. Phys. Chem. 1990, 94, 6431.

13. Rigutto, M. S.; Vanbekkum, H.; Appl. Catal. 1991, 68, L1.

14. Centi, G.; Perathoner, S.; Trifiro, F.; Aboukais, A.; Aissi, C. F.; Guelton, M.; J. Phys. Chem. 1992, 96, 2617.

15. Sen, T.; Ramaswamy, V.; Ganapathy, S.; Rajamohanan, P. R.; Sivasanker, S.; J. Phys. Chem. 1996, 100, 3809.

16. Venkatathri, N.; Vinod, M. P.; Vijayamohanan, K.; Sivasanker, S.; J. Chem. Soc. Chem. Commun. 1996, 92, 473.

17. Anpo, M.; Higashimoto, S.; Matsuoka, M.; Zhanpeisov, N.; Shioya, Y.; Dzwigaj, S.; Che, M.; Catal. Today 2003, 86, 287.

18. Prakash, A. M.; Kevan, L.; J. Phys. Chem. B 2000, 104, 6860.

19. Kresge, C. T.; Leonowicz, M. E.; Roth, W. J.; Vartuli, J. C.; Beck, J. S.; Nature 1992, 359, 710.

20. Reddy, K. M.; Moudrakovski, I.; Sayari, A.; J. Chem. Soc. Chem. Commun. 1994, 1059.

21. Zhang, W. Z.; Pinnavaia, T. J.; Catal. Lett. 1996, 38, 261.

22. Reddy, J. S.; Sayari, A.; J. Chem. Soc. Chem. Commun. 1995, 2231.

23. Lee, D. S.; Liu, T. K.; J. Sol-Gel Sci. Technol. 2002, 23, 15.

24. Gunduz, G.; Dimitrova, R.; Yilmaz, S.; Dimitrov, L.; Appl. Catal., A 2005, 282, 61 .

25. Albuquerque, A.; Marchese, L.; Lisi, L.; Pastore, H. O.; J. Catal. 2006, $241,367$.

26. Wark, M.; Koch, M.; Bruckner, A.; Grunert, W.; J. Chem. Soc. Chem. Commun. 1998, 94, 2033.

27. Albuquerque, A.; Pastore, H. O.; Marchese, L.; Stud. Surf. Sci. Catal. 2005, 158, 901.

28. Centi, G.; Trifiro, F.; Appl. Catal., A 1996, 143, 3.

29. Trujillo, C. A.; Uribe, U. N.; Knops Gerrits, P. P.; Oviedo, L. A.; Jacobs, P. A.; J. Catal. 1997, 168, 1.

30. Okamoto, M.; Luo, L.; Labinger, J. A.; Davis, M. E.; J. Catal. 2000, 192, 128.

31. Dimitrova, R.; Neinska, Y.; Mihalyi, M.; Pal-Borbely, G.; Spassova, M.; Appl. Catal., A 2004, 266, 123.

32. Lacheen, H. S.; Iglesia, E.; J. Phys. Chem. B 2006, 110, 5462.

33. Dzwigaj, S.; Peltre, M. J.; Massiani, P.; Davidson, A.; Che, M.; Sen, T.; Sivasanker, S.; Chem. Commun. 1998, 87.

34. Dzwigaj, S.; Matsuoka, M.; Franck, R.; Anpo, M.; Che, M.; J. Phys. Chem. B 1998, 102, 6309.

35. Dzwigaj, S.; Matsuoka, M.; Anpo, M.; Che, M.; J. Phys. Chem. B 2000, 104, 6012

36. Dzwigaj, S.; El Malki, E. M.; Peltre, M. J.; Massiani, P.; Davidson, A.; Che, M.; Top. Catal. 2000, 11, 379.

37. Dzwigaj, S.; Massiani, P.; Davidson, A.; Che, M.; J. Mol. Catal., A 2000, $155,169$.

38. Dzwigaj, S.; Matsuoka, M.; Anpo, M.; Che, M.; Catal. Lett. 2001, 72, 211.

39. Dzwigaj, S.; Che, M.; J. Phys. Chem. B 2005, 109, 22167.

40. Ivanova, E.; Hadjiivanov, K.; Dzwigaj, S.; Che, M.; Microporous Mesoporous Mater. 2006, 89, 69.

41. Gora-Marek, K.; Datka, J.; Dzwigaj, S.; Che, M.; J. Phys. Chem. B 2006, 110,6763 
42. Dzwigaj, S.; Matsuoka, M.; Anpo, M.; Che, M.; Microporous Mesoporous Mater. 2006, 93, 248.

43. Concepcion, P.; Lopez Nieto, J. M.; Perez Pariente, J.; Catal. Lett. 1993, $19,333$.

44. Concepcion, P.; Nieto, J. M. L.; Perez Pariente, J.; J. Mol. Catal., A 1995, 97, 173

45. Blasco, T.; Concepcion, P.; Nieto, J. M. L.; Perez Pariente, J.; J. Catal. 1995, 152, 1 .

46. Julbe, A.; Farrusseng, D.; Jalibert, J. C.; Mirodatos, C.; Guizard, C.; Catal. Today 2000, 56, 199.

47. Santamaria-Gonzalez, J.; Luque-Zambrana, J.; Merida-Robles, J.; Maireles-Torres, P.; Rodriguez-Castellon, E.; Jimenez-Lopez, A.; Catal. Lett. 2000, 68, 67 .

48. Zhou, R.; Cao, Y.; Yan, S. R.; Deng, J. F.; Liao, Y. Y.; Hong, B. F.; Catal. Lett. 2001, 75, 107.

49. Wang, Y.; Zhang, Q. H.; Ohishi, Y.; Shishido, T.; Takehira, K.; Catal. Lett. 2001, 72, 215.

50. Dzwigaj, S.; Gressel, I.; Grzybowska, B.; Samson, K.; Catal. Today 2006, 114, 237.

51. Kapoor, M. P.; Gallot, J. E.; Raj, A.; Kaliaguine, S.; J. Chem. Soc. Chem. Commun. 1995, 2281.

52. Raj, A.; Roberge, D.; Kaliaguine, S.; Iwamoto, S.; Inui, T.; Chem. Commun. 1996, 531.

53. Mal, N. K.; Ramaswamy, A. V.; Appl. Catal., A 1996, 143, 75.

54. Singh, A. P.; Selvam, T.; Appl. Catal., A 1996, 143, 111.

55. Teixeira-Neto, A. A.; Marchese, L.; Landi, G.; Lisi, L.; Pastore, H. O.; Catal. Today 2008, 133, 1.

56. Kannan, S.; Sen, T.; Sivasanker, S.; J. Catal. 1997, 170, 304.

57. Higashimoto, S.; Matsuoka, M.; Zhang, S. G.; Yamashita, H.; Kitao, O.; Hidaka, H.; Anpo, M.; Microporous Mesoporous Mater. 2001, 48, 329.

58. Wang, C. B.; Deo, G.; Wachs, I. E.; J. Catal. 1998, 178, 640.

59. Sen, T.; Rajamohanan, P. R.; Ganapathy, S.; Sivasanker, S.; J. Catal. 1996, $163,354$.

60. Anand, R.; Shevade, S. S.; Ahedi, R. K.; Mirajkar, S. P.; Rao, B. S.; Catal. Lett. 1999, 62, 209.

61. Shevade, S. S.; Rao, B. S.; J. Mater. Chem. 1999, 9, 2459.

62. Rigutto, M. S.; van Bekkum, H.; J. Mol. Catal. 1993, 81, 77.

63. Concepcion, P.; Lopez Nieto, J. M.; Perez-Pariente, J.; J. Mol. Catal., A 1995, 97, 173.
64. Tian, P.; Liu, Z. M.; Wu, Z. B.; Xu, L.; He, Y. L.; Catal. Today 2004, 93-95, 735

65. Elangovan, S. P.; Arabindoo, B.; Krishnasamy, V.; Murugesan, V.; J. Chem. Soc., Faraday Trans. 1995, 91, 4471.

66. Elangovan, S. P.; Murugesan, V.; J. Mol. Catal. A 1997, 118, 301.

67. Zhang, W. Z.; Wang, J. L.; Tanev, P. T.; Pinnavaia, T. J.; Chem. Commun. 1996, 979.

68. Selvam, P.; Dapurkar, S. E.; J. Catal. 2005, 229, 64.

69. Selvam, P.; Dapurkar, S. E.; Appl. Catal., A 2004, 276, 257.

70. Pena, M. L.; Dejoz, A.; Fornes, V.; Rey, E.; Vazquez, M. I.; Nieto, J. M. L.; Appl. Catal., A 2001, 209, 155.

71. Zhang, Q. H.; Yang, W.; Wang, X. X.; Wang, Y.; Shishido, T.; Takehira, K.; Microporous Mesoporous Mater. 2005, 77, 223.

72. Williams, T.; Beltramini, J.; Lu, G. Q.; Microporous Mesoporous Mater. 2006, 88, 91 .

73. Lee, C. W.; Lee, W. J.; Park, Y. K.; Park, S. E.; Catal. Today 2000, 61, 137.

74. Shiraishi, Y.; Naito, T.; Hirai, T.; Ind. Eng. Chem. Res. 2003, 42, 6034.

75. Volpe, M.; Tonetto, G.; de Lasa, H.; Appl. Catal., A 2004, 272, 69.

76. Habersberger, K.; Jiru, P.; Tvaruzkova, Z.; Centi, G.; Trifiro, F.; React. Kinet. Catal. Lett. 1989, 39, 95.

77. Reddy, K. R.; Ramaswamy, A. V.; Ratnasamy, P.; J. Chem. Soc. Chem. Commun. 1992, 1613.

78. Tuel, A.; Bentaarit, Y.; Zeolites 1994, 14, 18.

79. Bhaumik, A.; Dongare, M. K.; Kumar, R.; Microporous Mater. 1995, 5 , 173.

80. Chien, S. H.; Ho, J. C.; Mon, S. S.; Zeolites 1997, 18, 182.

81. Rocha, J.; Brandao, P.; Lin, Z.; Anderson, M. W.; Alfredsson, V.; Terasaki, O.; Angew. Chem., Int. Ed. 1997, 36, 100.

82. Brandao, P.; Philippou, A.; Hanif, N.; Ribeiro-Claro, P.; Ferreira, A.; Anderson, M. W.; Rocha, J.; Chem. Mater. 2002, 14, 1053.

83. Morey, M.; Davidson, A.; Eckert, H.; Stucky, G.; Chem. Mater. 1996, 8, 486.

84. Van Der Voort, P.; Morey, M.; Stucky, G. D.; Mathieu, M.; Vansant, E. F.; J. Phys. Chem. B 1998, 102, 585.

85. Gomez, S.; Garces, L. J.; Villegas, J.; Ghosh, R.; Giraldo, O.; Suib, S. L.; J. Catal. 2005, 233, 478. 